\title{
CARBON SEQUESTRATION POTENTIAL IN ABOVEGROUND BIOMASS OF THONG PHA PHUM NATIONAL FOREST, THAILAND
}

\author{
J. TERAKUNPISUT ${ }^{1}-$ N. GAJASENI ${ }^{2} *-$ N. RUANKAWE ${ }^{2} *$ \\ ${ }^{1}$ Zoology Major, Faculty of Liberal Arts and Science, Kasetsart University Kamphaeng Saen \\ Campus, Nakornpratom 73140, Thailand \\ (phone: +66-1-362-8696, fax: +66-2-942-8010 ext 4613) \\ ${ }^{2}$ Biology Department, Faculty of Science, Chulalongkorn University, Bangkok 10330, Thailand \\ (phone: +66-2-218-5360, fax: +66-2-218-5386) \\ e-mail: tjiranan@hotmail.com \\ (Received $1^{\text {st }}$ May 2006; accepted $13^{\text {th }}$ May 2007)
}

\begin{abstract}
This study assessed the potential of carbon sequestration on aboveground biomass in the different forest ecosystems in Thong Pha Phum National Forest, Thailand. The assessment was based on a total inventory for woody stem at $\geq 4.5 \mathrm{~cm}$ diameter at breast height (DBH). Aboveground biomass was estimated using allometric equation and aboveground carbon stock was calculated by multiplying the 0.5 conversion factor to the biomass. As the results, carbon sequestration showed varied in different types of forests. Tropical rain forest (Ton Mai Yak station) higher carbon stock than dry evergreen forest (KP 27 station) and mixed deciduous forest (Pong Phu Ron station) as $137.73 \pm 48.07,70.29 \pm 7.38$ and 48.14 \pm 16.72 tonne $\mathrm{C} / \mathrm{ha}$, respectively. Habitat variability caused differences of biomass accumulation, species composition and the allometric relationships of forests. In the study area, all forest had a similar pattern of tree size class, with a dominant size class at $\geq 4.5-20 \mathrm{~cm}$. The $\geq 4.5-20 \mathrm{~cm}$ trees potentially provided a greater carbon sequestration in tropical rain forest and dry evergreen forest while the size of $>20-40 \mathrm{~cm}$ gave potentially high carbon sequestration in mixed deciduous forest. Due to the trees have the lowest carbon sequestration but they considerably grow up to the further size classes. Apparently, they will be able to increase more biomass accumulation and store more carbon. In conclusion, the greatest carbon sequestration potential is in mixed deciduous forest and followed by tropical rain forest and dry evergreen forest in Thong Pha Phum National Forest. Finally, the appropriate forest ecosystem management can be an alternative solution for carbon dioxide reduction in terms of carbon sink role.
\end{abstract}

Keywords: carbon stock, biomass, allometric equation, diameter at breast height

\section{Introduction}

Increasingly convincing evidences show that the Earth is getting warmer and in the future warming could have serious effects on affect human [13]. Atmospheric concentration of carbon dioxide $\left(\mathrm{CO}_{2}\right)$, the primary and best studied greenhouse gas, has increased by about $30 \%$ from the start of the industrial revolution to 1992 due to fossil fuel combustion and change in land use [14]. The ultimate objective of The United Nations Framework, in which Thailand is a member, is to stabilize the atmospheric greenhouse gas concentrations at the level that will not cause dangerous anthropogenic interference with the climate system. The emission reduction of greenhouse gases from a member of industrialized countries called for in Kyoto Protocol. Thailand has ratified Kyoto Protocol since August 28, 2002; therefore, the country will voluntarily participate in $\mathrm{CO}_{2}$ reduction. There are two alternatives to reduce $\mathrm{CO}_{2}$ : decreasing carbon source and increasing carbon sink. 
The world's forests are prominent sites to study of climate change, not only in terms of total net carbon emissions but also in terms of global storage capacity, important for climatic regulation. Under the processes of nutrient uptake and cycling in forest ecosystems and thus highly influenced by changes in temperature or precipitation regimes as well as by changes in the atmospheric $\mathrm{CO}_{2}$ concentration.

Therefore, this study is focusing on carbon sequestration, specifically in terms of aboveground biomass and carbon stock. The estimates of carbon stock are also important for scientific and management issues such as forest productivity, nutrient cycling, and inventories of fuel wood and pulp. In addition, aboveground biomass is a key variable in the annual and long term changes in the global terrestrial carbon cycle and other earth system interactions. It is also important in the modelling of carbon uptake and redistribution within ecosystems. Of most interest is live wood biomass, which is involved in the regulation of atmospheric carbon concentrations. Thus, its dynamics must be understood if annual spatial variations are to be related to spatial weather and climate variables. Other computations, which require an accurate estimate of biomass along with carbon emission and carbon sequestration rates, are defining the carbon status and flux in a given geopolitical unit for the assessment, for example carbon taxes and similar international $\mathrm{CO}_{2}$ mitigation measures.

\section{Materials and methods}

\section{Study area}

The study was located at Thong Pha Phum District, Kanchanaburi Province, Thailand which can be classified into three forest types as tropical rain forest, dry evergreen forest and mixed deciduous forest. Three sampling sites were selected, one from each of three forest types. The geographical characteristics of the sampling sites were recorded in (Table 1.)

Aboveground biomass assessment was carried out in three natural forests from November 2002 to April 2003. Average annual rainfall is $1,650 \mathrm{~mm}$, which rainy season normally started from April to October [18]. Average annual temperature is $25^{\circ}$ $\mathrm{C}$ that distributed the range of $9.3^{\circ} \mathrm{C}$ to $42.2^{\circ} \mathrm{C}$ in the natural forest. In the study area, the species area curves of all three forests were available at different densities and a square mesh of one plot. Each plot in tropical rain forest, dry evergreen forest and mixed deciduous forest had a square plot with $80 \times 80,80 \times 80$, and $50 \times 50 \mathrm{~m}^{2}$, respectively. The replications of plot in tropical rain forest at Ton Mai Yak were 3 plots, dry evergreen forest at KP 27 were 4 plots, and mixed deciduous forest at Phong Phu Ron station were 5 plots.

Table 1. Geographical coordination of the study area and forest types at Thong Pha Phum National Forest.

\begin{tabular}{|c|c|c|c|}
\hline Name & Location & Forest type & $\begin{array}{c}\text { No. sampled } \\
\text { plot }\end{array}$ \\
\hline Ton mai yak station & $1609720 \mathrm{~N}$ and $0470402 \mathrm{E}$ & Tropical rain forest & $3\left(80 \times 80 \mathrm{~m}^{2}\right)$ \\
\hline KP 27 station & $1613596 \mathrm{~N}$ and 0470585 E & Dry evergreen forest & $4\left(80 \times 80 \mathrm{~m}^{2}\right)$ \\
\hline Phong phu ron station & $1619296 \mathrm{~N}$ and 0474970 E & $\begin{array}{c}\text { Mixed deciduous } \\
\text { forest }\end{array}$ & $5\left(50 \times 50 \mathrm{~m}^{2}\right)$ \\
\hline
\end{tabular}




\section{Sampling methods}

Three different forests were selected on the basis of total inventory for woody stems $\mathrm{DBH} \geq 4.5 \mathrm{~cm}$. SILVIC Program was used for tree height estimation $\left(\mathrm{H}_{\mathrm{t}}\right)$ by using a minimum of 40 randomly trees in various sizes in the sample plots as following the equation by [15]:

$$
1 / \mathrm{H}_{\mathrm{t}}=1 / \mathrm{A}(\mathrm{DBH})^{\mathrm{h}}+1 / \mathrm{H}^{*}
$$

Where $\quad \mathrm{Ht}=$ height of tree $(\mathrm{m}), \mathrm{DBH}=$ diameter at breast height $(\mathrm{cm}), \mathrm{A}, \mathrm{h}, \mathrm{H}^{*}=$ constant

After the trees were harvested, diameter and height were estimated with SILVIC Program, were applied to these data allometric regression equations to estimate the total aboveground biomass. Aboveground biomass was calculated by summing the stem, branches and leaf mass of individual trees, using allometric equations of [19] for tropical rain forest and dry evergreen forest, and [16] for mixed deciduous forest, as the following:

And

$$
\begin{array}{ll}
\text { Stem }(\mathrm{Ws}) & =0.0509 *\left(\mathrm{D}^{2} \mathrm{H}\right)^{0.919} \\
\text { Branch }(\mathrm{Wb}) & =0.00893 *\left(\mathrm{D}^{2} \mathrm{H}\right)^{0.977} \\
\text { Leaf }(\mathrm{Wl}) & =0.0140 *\left(\mathrm{D}^{2} \mathrm{H}\right)^{0.669}
\end{array}
$$

$$
\begin{array}{ll}
\text { Stem }(\mathrm{Ws}) & =0.0396 *\left(\mathrm{D}^{2} \mathrm{H}\right){ }^{0.9326} \ldots \ldots \ldots[16] \\
\text { Branch }(\mathrm{Wb}) & =0.003487 *\left(\mathrm{D}^{2} \mathrm{H}\right){ }^{1.027} \\
\text { Leaf }(\mathrm{Wl}) & =((28.0 / \mathrm{WS}+\mathrm{WB})+0.025)^{-1}
\end{array}
$$

Where $\mathrm{Ws}=$ stem mass $(\mathrm{kg} /$ individual tree $), \mathrm{Wb}=$ branches mass $(\mathrm{kg} /$ individual tree), $\mathrm{Wl}=$ leaf mass ( $\mathrm{kg} / \mathrm{individual}$ tree)

The carbon content was calculated by multiplying the 0.5 conversion factors to aboveground biomass $[1,3,12,8,5]$

\section{Results and discussion}

Aboveground biomass was estimated at the different forest types in order to indicate the proportion of biomass. It was found that $\mathrm{DBH}$ and height of trees were distributed different size classes. The characteristics of size class of three different forests were compared in (Figure 1), showing the relationship between DBH and tree density in each size class. This would tend to make the biomass differences even greater. The frequency distribution curves of DBH were all L-shaped, the frequency patterns were more or less exponentially toward larger diameter classes with a maximum at the left- end or smallest DBH size classes. 


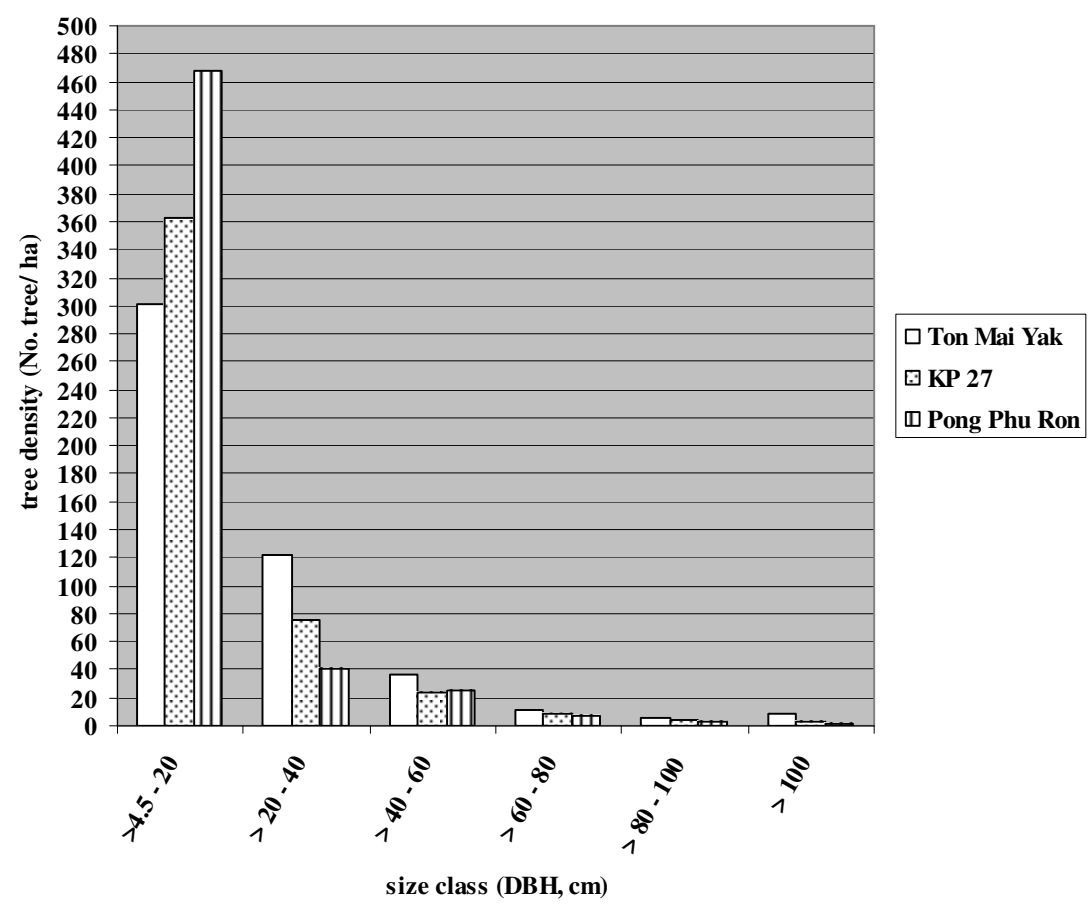

Figure 1. Tree density in different size classes at Ton Mai Yak station, KP 27 station, and Pong Phu Ron station sampling sites.

Aboveground biomass accumulation was highest in tropical rain forest (Figure 2); while the aboveground biomass in dry evergreen forest was lower than mixed deciduous forest at DBH size class over $100 \mathrm{~cm}$. Although mixed deciduous forest had the high number of tree and species, but most of trees were smaller than $20 \mathrm{~cm}$ in a typical uneven - aged stand and caused the lowest individual volume and biomass. The main conclusion showed an opposite relationship between biomass and tree size class. The most aboveground biomass accumulation was found in big trees of size class at $\geq 80$ 100 and $\geq 100 \mathrm{~cm}$. Because these trees had the highest stem volume and large diameter, they also had the lowest number of tree densities.

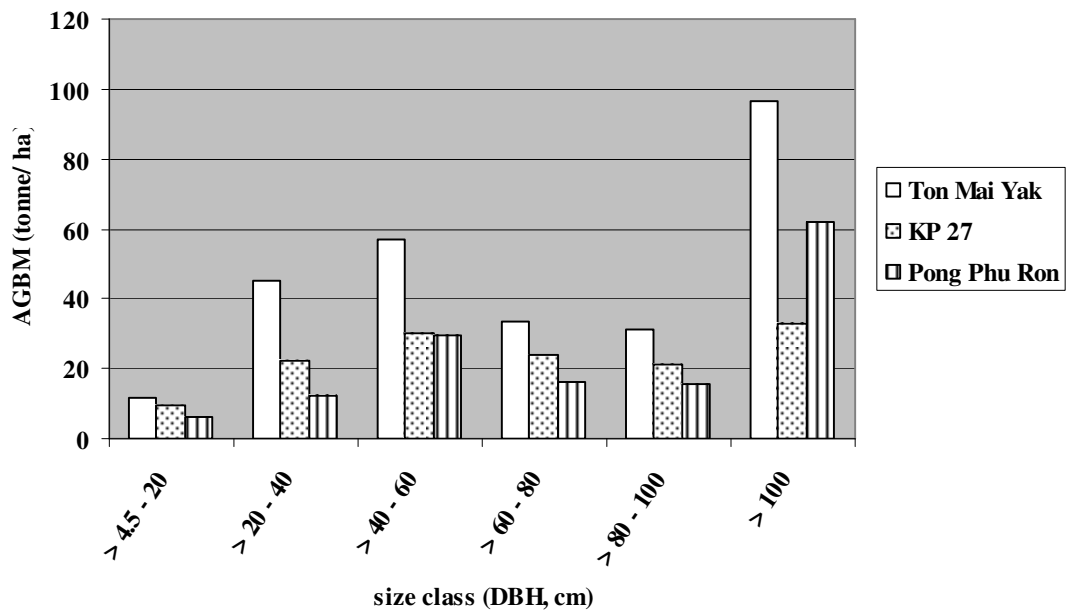

Figure 2. Aboveground biomass in different tree size classes in Ton Mai Yak station, KP 27 station, and Pong Phu Ron station sampling sites. 
The percentage data of tree density and aboveground biomass were presented in Table 2 and showed the similar pattern of tree density and aboveground biomass in each size class. In the sample plot, all forests had a tree size class, with the dominant size class at $\geq 4.5-20 \mathrm{~cm}$, were accounted for 85.88, 76.22 and $61.98 \%$ at Pong Phu Ron station, KP 27, and Ton Mai Yak station, respectively. On the other hand, the size class of all forests had the lowest aboveground biomass accumulation that comprised approximately ranging from $4.17-6.71 \%$ of the total biomass density in this study, due to low stem volume, low basal area and short trees with small diameters.

Comparison of the size class distribution and aboveground biomass showed some evidences of biomass reduction in larger size classes, $>60-80$ and $>80-100 \mathrm{~cm}$, resulting from selective logging in this area. Logging in excess of regrowth was also a significant cause of loss, particularly in Asian forests [17] and usually destroyed the small size of tree during the tree felling and log dragging process [10], which reflected the reduction of classes $>20-40$ and $>40-60 \mathrm{~cm}$ size classes in the mixed deciduous forest. In the sample plot, all forests had a similar pattern of tree size class, with a dominant size class at $\geq 4.5-20 \mathrm{~cm}$.

Table 2. A comparison of the percentage of tree density and carbon sequestration potential in each size class in the different study sites.

\begin{tabular}{|c|c|c|c|}
\hline \multirow{2}{*}{$\begin{array}{l}\text { Size class } \\
\quad(\mathrm{cm})\end{array}$} & Tropical rain forest & Dry evergreen forest & Mixed deciduous forest \\
\hline & $\begin{array}{l}\text { Ton Mai Yak station } \\
\text { Tree density C-storage } \\
(\%)\end{array}$ & \begin{tabular}{cc}
\multicolumn{2}{c}{ (KP 27 station) } \\
Tree density & C-storage \\
$(\%)$ & $(\%)$
\end{tabular} & $\begin{array}{cc}\text { (Pong Phu Ron station) } \\
\text { Tree density } & \text { C-storage } \\
(\%) & (\%)\end{array}$ \\
\hline$\geq 4.5-20$ & 62.0 & 76.22 & 85.88 \\
\hline$>20-40$ & 25.2 & 16.05 & 8.82 \\
\hline$>40-60$ & 20.7 & 21.42 & 20.83 \\
\hline$>60-80$ & 12.1 & 17.03 & 11.31 \\
\hline$>80-100$ & 11.4 & 15.19 & 10.89 \\
\hline$>100$ & 35.2 & 23.61 & 43.67 \\
\hline
\end{tabular}

Carbon sequestration potential in the different forest types to be correlated to DBH size class (Table 2). In tropical rain forest and dry evergreen forest, the main tree size classes that had a great potential in carbon sequestering from small up to medium tree size at $\geq 4.5-20$ up to $>40-60 \mathrm{~cm}$. While, the main tree size classes that had the highest potential in carbon sequestering in mixed deciduous forest from small up to medium tree size at $>20-40 \mathrm{~cm}$ up to $>40-60 \mathrm{~cm}$.

For example, in Ton Mai Yak station, the smallest tree in size class $\geq 4.5-20 \mathrm{~cm}$ had biomass accumulation or carbon sequestration potential only $4.2 \%$. When trees considerably grow up to further size class at $>20-40 \mathrm{~cm}$, these trees had a highest carbon sequestration potential. For the size class at $>40-60 \mathrm{~cm}$, trees had a high carbon sequestration potential but not as much as in size class at $>20-40 \mathrm{~cm}$. In accordance with dry evergreen forest, trees in size class $\geq 4.5-20 \mathrm{~cm}$ were able to grow fast and store more carbon. While trees in mixed deciduous forest had potential to grow fast and store more carbon at size class of $>20-40 \mathrm{~cm}$.

The results of aboveground biomass and carbon sequestration in Table 3 that showed the average aboveground biomass in Ton Mai Yak station (tropical rain forest), KP 27 station (dry evergreen forest) and Pong Phu Ron station (mixed deciduous forest) were 275.46 $\pm 96.15,140.58 \pm 14.76$ and 96.28 \pm 33.44 tonne/ha, respectively. Aboveground 
biomass varied from plot to plot in forest area due to different stage of forest growth cycle, habitat variation, and tree density. The stem weight, especially tree biomass of bigger trees, is the largest component of a forest biomass [16].

In this study, the results included only the tree components of aboveground biomass. In general, root biomass is approximately $25 \%$ of aboveground biomass [7], so the calculated root biomass in Ton Mai Yak station, KP 27 station and Pong Phu Ron station are about $68.87,35.15$, and 24.07 respectively.

Carbon content was calculated from aboveground biomass with the method used by $[1,3,12,8,5]$. Carbon content would be about $50 \%$ of the amount of total aboveground biomass. Therefore, the aboveground carbon sequestration of three forest types are calculated, the carbon is stored at Ton Mai Yak station as $137.73 \pm 48$ and follow by KP 27 and Pong Phu Ron station are 70.81, 70.29 \pm 7.38 and 48.14 \pm 16.72 tonne $\mathrm{C} /$ ha respectively (Table 3 ).

Table 3. Aboveground biomass of tree and carbon sequestration at three study sites.

\begin{tabular}{|c|c|c|c|c|c|c|c|}
\hline $\begin{array}{c}\text { Study } \\
\text { sites }\end{array}$ & $\begin{array}{c}\text { Tree } \\
\text { density } \\
\text { (No./ha) }\end{array}$ & $\begin{array}{c}\text { Stem } \\
\text { mass } \\
\text { (tonne/ha) }\end{array}$ & $\begin{array}{c}\text { Branch } \\
\text { mass } \\
\text { (tonne/ha) }\end{array}$ & $\begin{array}{c}\text { Leaf mass } \\
\text { (tonne/ha) }\end{array}$ & $\begin{array}{c}\text { Total } \\
\text { AGBM } \\
\text { (tonne/ha) }\end{array}$ & $\begin{array}{c}\text { Carbon } \\
\text { sequestration } \\
\text { (tonne C/ha) }\end{array}$ & $\begin{array}{c}\text { Calculate } \\
\text { root } \\
\text { biomass* } \\
\text { (tonne } \\
\text { C/ha) }\end{array}$ \\
\hline $\begin{array}{c}\text { Ton Mai } \\
\text { Yak } \\
\text { station }\end{array}$ & $\begin{array}{c}745 \pm \\
142.3\end{array}$ & $\begin{array}{c}217.241 \pm \\
52.62\end{array}$ & $\begin{array}{c}54.667 \pm \\
40.960\end{array}$ & $\begin{array}{c}3.554 \pm \\
0.790\end{array}$ & $\begin{array}{c}275.46 \pm \\
96.15\end{array}$ & $\begin{array}{c}137.73 \pm \\
48.07\end{array}$ & 34.43 \\
\hline $\begin{array}{c}\text { KP 27 } \\
\text { station }\end{array}$ & $560 \pm$ & $103.391 \pm$ & $34.911 \pm$ & $2.297 \pm$ & $140.58 \pm 1$ & $70.29 \pm 7.38$ & 17.57 \\
\hline $\begin{array}{c}\text { Pong Phu } \\
\text { Ron }\end{array}$ & $544 \pm$ & 11.16 & 30.487 & 0.493 & 4.76 & & \\
station & 98.3 & 50.63 & 29.96 & 0.005 & 44 & & \\
\end{tabular}

*Note: root biomass is approximately calculated as $25 \%$ of aboveground biomass [7]

Data on carbon sequestration in the different forest types showed that the highest amount of carbon was stored in the biomass of tropical rain forest at Ton Mai Yak station. Because tree sizes at Ton Mai Yak station were quite large when compared to other stations so calculated carbon sequestration are the highest in this station. It does not mean that other forest types are not important, because the mainly groups of small tree sizes at $\geq 4.5-20 \mathrm{~cm}$ will grow to bigger size in the near future. They will have greater potential for future sequestration if the forests are under appropriate management without human disturbance. Huston and Marland [11] showed that carbon sequestration depended not only on rates of productivity but also on the size of the tree. Disturbance of landscapes can result in rapid release of large amount of carbon that will be recaptured slowly as forest regrowth.

In (Table 4), the comparison of biomass accumulation and carbon sequestration in various forest types showed the largest biomass in the tropical rain forest and the lowest biomass in the mixed deciduous forest. The results from this study showed the range of aboveground biomass in tropical rain forest, dry evergreen forest and mixed deciduous forest as $275.46,140.48$, and 96.28 tonne/ha, with calculated carbon sequestration as 
137.73, 70.29, and 48.14 tonne C/ha. Ogawa et al. [16] reported aboveground biomass data of different forests in Thailand such as tropical rain forest, dry evergreen forest and mixed deciduous forest at 358, 126 and 311 tonne/ha, with calculated carbon sequestration as $179,60.30$, and 155.50 tonne/ha, based on direct measurement by destructive method of tropical rain forest in the Forest Reserve of Khao Chong, Trang Province of peninsular Thailand, as well as dry evergreen forest and mixed deciduous at Ping Kong, Chaing Mai Province. As the results of this study, carbon sequestration was considerably lower than the Ogawa et al. study, which may suggest that these forests were more disturbed and affected to change in forestland due to different initial time study, site qualities, carbon sequestering carrying capacities and reflected that the tropical rain forest in this study was an immature forest. Flint and Richards [9] studied that carbon sequestration was estimated in Southeast Asia including India, Thailand, Cambodia, Malaysia and Indonesia ranging from 17.5 tonne $\mathrm{C} /$ ha or less in severely degraded tropical dry forest to almost 350 tonne $\mathrm{C} / \mathrm{ha}$ in relatively undisturbed mature tropical rain forest. The lower biomass values often reflected an immature forest.

Brown and Lugo [3] summarized the total carbon sequestration estimates of tropical forest in three countries including Malaysia, Cameroon and Sri Lanka, ranging from 76.50 tonne $\mathrm{C} / \mathrm{ha}$ in disturbed tropical rain forest to 223 tonne $\mathrm{C} / \mathrm{ha}$ in relatively undisturbed mature tropical rain forest based on direct measurement was the highest in Malaysia (112.5-223 tonne C/ha), followed by Cameroon (119-170.5 tonne C/ha), and Sri Lanka (76.5-110.5 tonne C/ha). The ranges of biomass lower than the other forest areas often reflected an immature forest, which may suggest that it due to human population pressure.

Table 4. A schematic of aboveground biomass and carbon sequestration in different forest types between this study and other studies.

\begin{tabular}{|c|c|c|c|c|c|c|c|}
\hline \multirow[b]{3}{*}{ Thailand } & \multicolumn{2}{|c|}{ Tropical rain forest } & \multicolumn{2}{|c|}{$\begin{array}{c}\text { Dry evergreen } \\
\text { forest }\end{array}$} & \multicolumn{2}{|c|}{ Mixed deciduous forest } & \multirow[t]{2}{*}{ Source } \\
\hline & $\begin{array}{c}\text { AGBM } \\
\text { (tonne/ha) }\end{array}$ & $\begin{array}{c}\text { C-stock } \\
\text { onne C/ha) }\end{array}$ & $\begin{array}{c}\text { AGBM } \\
\text { (tonne/ } \\
\text { ha) }\end{array}$ & $\begin{array}{r}\text { C-stock } \\
\text { (tonne } \\
\text { C/ha) }\end{array}$ & $\begin{array}{r}\text { AGBM } \\
\text { (tonne/h }\end{array}$ & $\begin{array}{c}\text { C-stock } \\
\text { (tonne /ha) }\end{array}$ & \\
\hline & 275.46 & 137.73 & 140.58 & 70.29 & 96.28 & 48.14 & $\begin{array}{l}\text { This } \\
\text { study }\end{array}$ \\
\hline Thailand & 358 & 179 & 126 & 60.30 & 311 & 155.50 & [16] \\
\hline Thailand & - & - & 252 & 126 & & - & [10] \\
\hline Thailand & - & - & - & - & $31.95-$ & $\begin{array}{l}15.97-87.75 \\
5.50\end{array}$ & [20] \\
\hline Malaysia & $225-446$ & $112.5-223$ & - & - & & - & [3] \\
\hline Cameroon & $238-341$ & $119-170.5$ & - & - & & - & \\
\hline Sri Lanka & $153-221$ & $76.5-110.5$ & - & - & & - & \\
\hline
\end{tabular}

By comparison of the carbon sequestration of tropical rain forest between this study and the study by [3], the result showed that the average total aboveground biomass in Thailand was 137.73 tonne $\mathrm{C} / \mathrm{ha}$, which is in the range of carbon sequestration in 
Malaysia and Cameroon. From annual precipitation data of Thailand, Malaysia and Cameroon as 1400, 2000 and $3000 \mathrm{~mm} / \mathrm{yr}$., respectively this possibly caused the carbon sequestering capacity [4].

Another factor that possibly caused of sequestered carbon lower than the other forest areas is tree height. Ogawa et al. [16] reported the calculated carbon sequestration of tropical rain forest at Khao Chong Forest Reserve, Thailand was 179 tonne C/ha that lower than calculated biomass from Malaysia because of the difference in tree height. The tallest tree actually measured there was only $36 \mathrm{~m}$ in height, whereas the maximum tree height of tropical rain forest in Malaysia often reaches $60 \mathrm{~m}$. Therefore, plant biomass in Malaysia was greater than here. Thus, the accuracy to estimate biomass by used allometric equations with containing both diameter and total height was better than diameter alone.

Regarding to Chittachumnonk et al. [6] studied on carbon sequestration of Teak plantation in Thailand, there were four study areas located in northern and western regions included Mae Mai Plantation at Muang District, Lampang, Thong Pha Phum Plantation at Thong Pha Phum District, Kanchnaburi, Sri Satchanalai Platation at Sri Satchanalai District, Sukhothai, and Khao Kra Yang Plantation, Wong Thong District, Phitsanulok. The study showed that all aboveground biomass of Teak plantation was equal to 78.15 tonne/ha or equivalent to $646,997.19$ tonne of total aboveground biomass of area, which total study area are $8,278.50$ ha. In the estimate of carbon sequestration of Teak plantation were 39.08 tonne $\mathrm{C} / \mathrm{ha}$. The carbon sequestration in Teak plantation was seemingly near by the natural mixed deciduous forest (48.14 tonne $\mathrm{C} / \mathrm{ha}$ ).

Viriyabuncha et al. [20] studied the evaluation system for carbon storage in forest ecosystems in Thailand. The result showed that the carbon sequestration at Doi Suthep - Pui National Park, Chiang Mai, evergreen forest and mixed deciduous forest were in the range 15.97-87.75 tonne $\mathrm{C} / \mathrm{ha}$. The maximum biomass was found in dry evergreen forest because it was old forest and have been strictly controlled the illegal logging. The minimum carbon sequestration was found in dry dipterocarp forest, which was a young forest. The study also showed carbon storage of mixed deciduous forest was in the range 15.97-87.75 tonne $\mathrm{C} / \mathrm{ha}$. Comparison of the carbon sequestration from this study and Viriyabuncha et al. [20] indicated the similar range and pattern that tropical rain forest sequestered carbon higher than dry evergreen forest and mixed deciduous forest as $137.73,70.29$ and 48.14 tonne $\mathrm{C} / \mathrm{ha}$, respectively. It indicated that carbon sequestration varies from forest types and age of forest and carbon sequestration potential was rely on tree size class. Mixed deciduous forest, tree sizes at $>40-60 \mathrm{~cm}$ had trend of carbon sequestration more than other size classes, while size class at $>20$ 40 and $>40-60 \mathrm{~cm}$ in dry evergreen forest and tropical rain forest had more carbon sequestration than other size classes.

In general conclusion from biomass and carbon sequestration studies, under the different disturbance, old growth forest had more carbon sequestration than logged forest and secondary forest, respectively. Each size class had a different carbon sequestration potential. Almost small up to medium sizes of trees had a greater potential for carbon sequestering than big trees due to the forest type because the growth rate will slowly in bigger trees. Therefore, to conserve and manage the small tree at $\geq 4.5-20$ and $>20-40 \mathrm{~cm}$ can considerably increase carbon sequestration potential in the near future. If the forest is deforested and changed by human activities, it will potentially cause the severe carbon loss to atmosphere from terrestrial ecosystems in relation to deforestation. In the summary, the estimation of aboveground biomass is based on data sets that 
consider only live trees, and do not consider litter or standing dead trees. Tropical forests tend to carry their biomass in the standing crop relatively more than temperate forests. Therefore, tropical forest inventories, which ignore dead matter, will be a small loss of proportion to total aboveground biomass than similar inventories in the temperate zone. According to carbon sequestration potential, it is clear that tropical forests have more effective in carbon sequestering than temperate forest due to net productivity differences [2]. Then tropical forest can play a major role in carbon dioxide reduction as carbon-sink.

\section{Conclusions}

Carbon sequestration varies from forest types and age of forest and carbon sequestration potential is rely on tree size class. Tropical rain forest has the highest potential of carbon sequestration and following by the dry evergreen forest and the mixed deciduous forest respectively. Tree sizes in mixed deciduous forest at $>40-60$ $\mathrm{cm}$ has trend of carbon sequestration potential more than other size classes, while size class at $>20-40$ and $>40-60 \mathrm{~cm}$ in dry evergreen forest and tropical rain forest has more carbon sequestration potential than other size classes. This evidence indicates the potential for growth to reach the climax stage of succession in the near future. These smaller trees are not the highest carbon sequestration potential but they are relevant in terms of their future potential to grow up. With high carbon sequestration potential in Thong Pha Phum National Forest, the Ministry of Natural Resources and Environmental must urgently consider to strictly protect and conserve these forests for sequestering atmospheric $\mathrm{CO}_{2}$, which can increase carbon sink into the natural forest. Thailand can contribute to reduce the problem of greenhouse effects regarding global warming and climate changes.

The problem in this study was that the available data on carbon sequestration in tropical forest were extremely limited and incomplete. In some cases, inappropriate field measurements, as a result forest biomass may be significantly under or overestimated. To resolve these uncertainties will require both improved practices with current field methods and new techniques for measuring processes to understanding of the carbon dynamics of the world's forests.

Acknowledgement. The authors gratefully acknowledge the financial support by Department of Biology, Chulalongkorn University Graduate School, and especially the BRT foundation for supporting this study at Thong Pha Phum Natural Forest. Thank for all researchers of Biodiversity Research and Training Program (BRT) and foresters at Thong Pha Phum District, Kanchanaburi Province, for all their supports assistance in the data collection, especially guiding appropriate forest inventories under the difficult field conditions. Also thank Mr. Chingchai Viriyabuncha at Forest Research Office, Royal Forest Department for training and providing useful data from the research of Teak plantation. The Development and Promotion of Science and Technology Talents Project provided support for Terakunpisut.

\section{REFERENCES}

[1] Atjay, G.L., Ketner, P., Duvignead, P. (1979): Terrestrial primary production and phytomass. - In B. Bolin; E.T. Degens; S. Kempe (eds.), The Global Carbon Cycle, pp. 129-182. New York: Wiley and Sons.

[2] Brown, S., Gillespie, A.J.R., Lugo, A.E. (1989): Biomass estimation methods for tropical forests with applications to forest inventory data. - Forest Science 35: 881-902. 
[3] Brown, S., Lugo, A.E. (1982): The storage and production of organic matter in tropical forests and their role in the global carbon cycle. - Biotropica 14: 161-187.

[4] Brown, S., Lugo, A.E. (1990): Tropical secondary forests. - Journal of Tropical Ecology 6: 1-32.

[5] Cannell, M.G.R., Milne, R. (1995): Carbon pools and sequestration in forest ecosystems in Britain. - Forestry 68: 361-378.

[6] Chittachumnonk, P., Sutthisrisinn, C., Samran, S., Viriyabuncha, C., Peawsad, K. (2002): Improving estimation of annual biomass increment and aboveground biomass of Teak plantation using site - specific allometric regressions in Thailand. - Royal forest department: Sivilculture Research Division.

[7] Cairns, M.A.S., Brown, S., Helmer, E.H., Baumgardner, G.A. (1997): Root biomass allocation in the world's upland forests. - Oecologia 111: 1-11.

[8] Dixon, R.K., Brown, S., Solomon, R.A., Trexler, M.C., Wisniewski, J. (1994): Carbon pools and flux of global forest ecosystems. - Science 263: 185-190.

[9] Flint, P.E., Richards, J.F. (1996): Trends in carbon content of vegetation in South and Southeast Asia associated with change in land use. - In V.H. Dale (ed.), Effects of LandUse Change on Atmospheric $\mathrm{CO}_{2}$ Concentrations, South and Southeast Asia as a Case Study, pp. 201-300., Berlin: Springer-Verlag.

[10] Gajaseni, N. (2000): An alternative approach to biodiversity evaluation: case study in the lower Mekong basin. - Doctoral dissertation, University of Edinburgh.

[11] Huston, M.A., Marland, G. (2003): Carbon management and biodiversity. - J. of Environmental Management [Online]. Available from: http://www.elsevier.com/ [2002, December, 22]

[12] Iversion, L. R., Brown, S., Prasad, A., Mitasova, H., Gillespie, A.J.R., Lugo, A.E. (1994): Use of GIS estimating potential and actual forest biomass for continental South and Southeast Asia. - In W. Dale (ed.), Effect of Land-Use Change on Atmospheric $\mathrm{CO}_{2}$ Concen-tration, pp 67-116., New York: Springer - Verlag.

[13] Mann, M.E., Brafley, R.S., Hughes, M.K. (1998): Global - scale temperature patterns and climate forcing over the past six centuries. - Nature 392: 779-787.

[14] Mark, T.H., Thomas, M.S. (2001): Carbon emissions and economic development: future trajectories based on historical experience. - Environment and Development Economics 6: 63-83.

[15] Ogawa, H., Yoda, K., Kira, T. (1961): A preliminary survey on the vegetation of Thailand. - Natural and Life in Southeast Asia 1: 21 - 157.

[16] Ogawa, H., Yoda, K., Ogino, K., Kira, T. (1965): Comparative ecological studies on three main type of forest vegetation in Thailand II. Plant Biomass. - Nature and Life in Southeast Asia 4: 49-80.

[17] Stiling, P. (1999): Ecology: theories and applications. $-3^{\text {rd }}$ ed. New Jersey: Prentice Hall.

[18] Suksawang, S. (1995): Site overview: Thong Pha Phum study site. - Proceedings of the International Workshop on the Changes of Tropical Forest Ecosystems: 33-37.

[19] Tsutsumi, T., Yoda, K., Sahunalu, P., Dhanmanonda, P., Prachaiyo, B. (1983): Forest: Felling, Burning and Regeneration. - In: K. Kyuma and C. Pairintra (eds.), Shifting cultivation, pp. 13-62. Tokyo.

[20] Viriyabuncha, C., Vacharangkura, T., Doangsrisen, B. (2002): The evaluation system for carbon storage in forest ecosystems in Thailand (I. aboveground biomass). - Sivilculture Research Division: Royal forest department. 